\title{
CrystEngComm
}

\section{Structural transformations in crystals induced by radiation and pressure. Part 1 . How pressure influences the intramolecular photochemical reactions in crystals $\dagger$}

Cite this: CrystEngComm, 2014, 16, 6039

\author{
Julia Bąkowicz* and Ilona Turowska-Tyrk
}

\begin{abstract}
The main aim of the studies in this paper is to gain knowledge on the path of structural transformations resulting from the photocyclization in 2-tert-butylphenylphenylmethanone crystals at low and high pressures and also to carry out a comparative analysis of the results at different pressures. This work is the first example of these types of studies in scientific literature. We determined the structure of: pure reactant crystals, i.e. only containing reactant molecules, at $0.1 \mathrm{MPa}, 0.55 \mathrm{GPa}, 1.27 \mathrm{GPa}$ and $1.50 \mathrm{GPa}$; pure product crystals, i.e. only containing product molecules, at $0.55 \mathrm{GPa}$ and $1.27 \mathrm{GPa}$; and partly reacted crystals (ten structures), i.e. containing both reactant and product molecules in various proportions to each other, at $0.1 \mathrm{MPa}$ (two structures), $0.55 \mathrm{GPa}$ (three structures), $1.27 \mathrm{GPa}$ (three structures) and $1.50 \mathrm{GPa}$ (two structures). The studies have shown that (a) there is no phase transition when an increase in pressure is imposed onto the crystals, (b) the unit cell parameters change non-linearly with an increase in pressure, (c) the photochemical reaction was conducted in a homogeneous manner in the examined crystals, (d) the reaction brings about different modes of changes in the unit cell parameters at different pressures (e) the reaction proceeds faster at the end rather than at the beginning regardless of the pressure imposed onto the crystals.
\end{abstract}

Received 13th February 2014, Accepted 28th March 2014

DOI: 10.1039/c4ce00320a

www.rsc.org/crystengcomm imposed by product molecules onto reactant molecules, (c) for most of the intramolecular reactions, the distance between the reactive atoms is constant during a long period of crystal transformation, (d) the orientations of the molecular fragments are changed as the transformation progresses; the

(a)

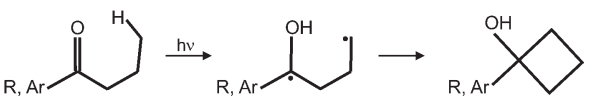

(b)

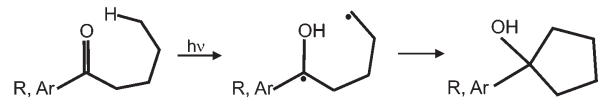

(c)<smiles>CC(C)(C)c1ccccc1C(=O)c1ccccc1</smiles>

Scheme 1 The photocyclization leading to (a) a four and (b) a fivemembered ring, with (c) the structure of the studied compound. 
biggest changes are $c a .20^{\circ}$, (e) the rate of the photochemical reactions depends on the concentration of the reactant molecules in the crystals and (f) the photochemical reactions bring about changes in the unit cell parameters, which is a result of changes in the crystal structures as the reactions progress.

\section{Chemical reactions in crystals at high pressure}

High-pressure techniques are important and useful tools in materials science. High pressure can induce various changes in crystal and molecular structures, for instance: shortening the distances between atoms and molecules, changing the molecular orientation, decreasing the cell volume and the volume of reaction cavities and also decreasing the values of atomic displacement parameters. ${ }^{15,16}$ High pressure can also bring about phase transitions and chemical reactions.

Studies of pressure-induced chemical reactions (without photo-induction) have been carried out for two decades. Until now, chemical reactions in crystals at high pressure have been reported for small molecular systems ${ }^{17}$ like nitrogen, carbon monoxide, carbon dioxide and nitrous oxide, for simple unsaturated compounds, in particular for hydrocarbons ${ }^{17-26}$ such as acetylene, ethylene, propylene, butadiene, for cyano derivatives and aromatics compounds ${ }^{17,18,27-34}$ like benzene and styrene. At high pressure, most of them undergo polymerization, addition and amorphization.

Some of the reported transformations were induced not only by high pressure, but simultaneously by electromagnetic radiation. In many cases the use of radiation at a high pressure enables different compounds with different properties to be obtained. Such a situation is observed for the polymerization of butadiene. ${ }^{17,18,35-37}$

Most chemical reactions at high pressure are studied using spectroscopic methods, usually IR and Raman spectroscopy, and very rarely, the final products and their structures are characterized by X-ray diffraction methods, usually powder diffraction.
Here, we present the results of an X-ray structure analysis on how pressure modifies structural changes brought about by the photochemical reaction in a crystal. This is the first example of such studies in scientific literature. The main aim of this research was accomplished by: (a) monitoring the deformations of the cell constants with the progression of the photochemical reaction at different pressures, (b) monitoring the deformations of the cell constants with an increase in pressure, i.e. without photo-induction, (c) monitoring the content of photoproduct molecules in crystals at different pressures, (d) analysing the changes in shape and geometry of the molecules in the crystals, (e) analysing the changes in molecular orientation. In order to achieve these goals, we determined pure reactant crystal structures, pure product crystal structures and also crystal structures of partly reacted crystals, i.e. containing both reactant and product molecules, at ambient and high pressures. The compound studied was 2-tert-butylphenylphenylmethanone.

\section{Experimental}

The studied compound was purchased from Sigma-Aldrich and recrystallized from a methanol:ethanol:water mixture (vol. $16: 3: 1$ ).

The experiments were carried out at ambient and high pressure and in the dark. In the high-pressure diffraction experiments, a high-pressure Boehler-Almax diamond anvil cell (DAC) was used. ${ }^{38}$ A single crystal of the studied compound, quartz and a small ruby chip were glued to a culet surface of the diamond anvil, covered by an inconel gasket (thickness: $0.3 \mathrm{~mm}$, hole diameter: $0.35 \mathrm{~mm}$ ), and filled with a glycerin : water mixture (vol. $3: 2$ ) or hydrostatic glycerin liquid. The quartz and ruby crystals acted as pressure sensors. The high pressure values in the DAC were estimated by the ruby fluorescence method ${ }^{39,40}$ and/or by the unit cell parameters of quartz. ${ }^{41}$ The DAC was mounted on a diffractometer and aligned using the gasket-shadow centering procedure. ${ }^{42}$ The sets of collected reflections contained data coming from

Table 1 Selected crystal data obtained at $0.55 \mathrm{GPa}$

\begin{tabular}{|c|c|c|c|c|c|}
\hline & $0.0 \% \mathrm{P}$ & $7.3 \% \mathrm{P}$ & $15.4 \% \mathrm{P}$ & $44.0 \% \mathrm{P}$ & $100.0 \% \mathrm{P}$ \\
\hline Chemical formula & $\mathrm{C}_{17} \mathrm{H}_{18} \mathrm{O}$ & $\mathrm{C}_{17} \mathrm{H}_{18} \mathrm{O}$ & $\mathrm{C}_{17} \mathrm{H}_{18} \mathrm{O}$ & $\mathrm{C}_{17} \mathrm{H}_{18} \mathrm{O}$ & $\mathrm{C}_{17} \mathrm{H}_{18} \mathrm{O}$ \\
\hline Formula weight & 238.31 & 238.31 & 238.31 & 238.31 & 238.31 \\
\hline Crystal system & Orthorhombic & Orthorhombic & Orthorhombic & Orthorhombic & Orthorhombic \\
\hline Space group & Pbca & Pbca & Pbca & Pbca & Pbca \\
\hline$a / \AA$ & $13.4655(10)$ & $13.4910(9)$ & $13.5452(14)$ & $13.649(3)$ & $13.8701(12)$ \\
\hline$b / \AA$ & $12.5668(9)$ & $12.5526(9)$ & $12.5231(13)$ & $12.434(2)$ & $12.3384(12)$ \\
\hline$c / \AA$ & $15.7267(10)$ & $15.7300(10)$ & $15.7348(15)$ & $15.727(2)$ & $15.6455(14)$ \\
\hline$V / \AA^{3}$ & $2661.2(3)$ & $2663.8(3)$ & $2669.1(5)$ & $2669.1(8)$ & $2677.5(4)$ \\
\hline$Z$ & 8 & 8 & 8 & 8 & 8 \\
\hline$D_{\mathrm{x}} / \mathrm{Mg} \mathrm{m}^{-3}$ & 1.190 & 1.188 & 1.186 & 1.186 & 1.182 \\
\hline$\mu / \mathrm{mm}^{-1}$ & 0.07 & 0.07 & 0.07 & 0.07 & 0.07 \\
\hline$T / \mathrm{K}$ & $299(2)$ & $299(2)$ & $299(2)$ & $299(2)$ & $299(2)$ \\
\hline Reflections collected & 14110 & 14156 & 14174 & 14127 & 14278 \\
\hline Reflections independent & 1704 & 1707 & 1711 & 1712 & 1718 \\
\hline Reflections observed & 957 & 942 & 866 & 763 & 931 \\
\hline$R_{\text {int }}$ & 0.083 & 0.085 & 0.097 & 0.121 & 0.092 \\
\hline$R, \mathrm{w} R\left(F^{2}>2 \sigma\left(F^{2}\right)\right), \mathrm{S}$ & $0.057,0.119,1.03$ & $0.068,0.142,1.04$ & $0.076,0.168,1.05$ & $0.108,0.260,1.04$ & $0.061,0.126,1.06$ \\
\hline$\Delta \rho_{\max }, \Delta \rho_{\min } / \mathrm{e}^{-3}$ & $0.16,-0.18$ & $0.23,-0.22$ & $0.20,-0.21$ & $0.29,-0.20$ & $0.19,-0.17$ \\
\hline
\end{tabular}


(a)
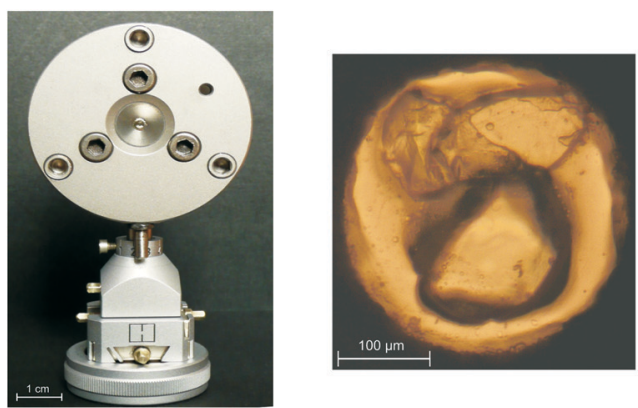

(b)
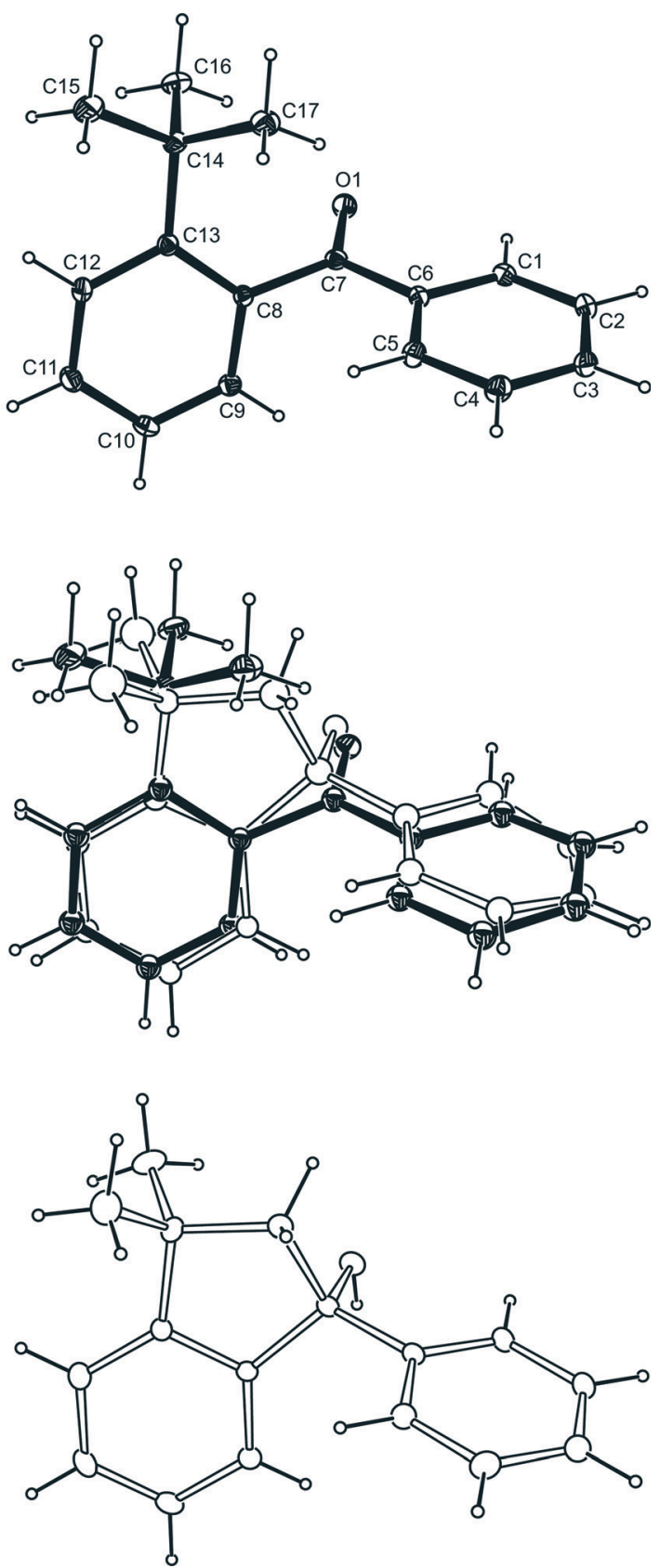

Fig. 1 (a) Diamond anvil cell (DAC) mounted on a goniometer head and crystals placed in the hole of a metal gasket at $0.55 \mathrm{GPa}$ : ruby, quartz and the studied compound. (b) ORTEP ${ }^{48}$ view of the molecules in the pure reactant (upper), partly reacted (middle) and pure product (lower) crystals at $0.55 \mathrm{GPa}$. the two diamonds, quartz, ruby and the studied compound. Nevertheless, it was possible to remove the reflections coming from both of the diamonds and to group the remaining sets into three separate parts: those coming from the quartz, those from the ruby and those from the studied compound. We used five different crystals of the studied compound. Four of them were closed in the DAC and one was mounted on a glass pin and measured at ambient pressure $(0.1 \mathrm{MPa})$. The values of high pressure were as follows: $0.55,0.90,1.27$ and $1.50 \mathrm{GPa}$. The CrysAlisPro program suite ${ }^{43}$ was used for data collection, UB matrices determination and data reduction. Additional corrections of the reflection intensities, associated with DAC absorption, were unnecessary.

We induced the photochemical reaction using UV radiation. The crystals were irradiated in steps using an $\mathrm{Hg} 100 \mathrm{~W}$ lamp equipped with a water filter and a WG-320 glass filter. The WG-320 filter blocked shorter and transmitted longer wavelengths: $0 \%$ transmittance for $\lambda<300 \mathrm{~nm}, c a$. $95 \%$ transmittance for $\lambda=350 \mathrm{~nm}$ and $100 \%$ transmittance for $\lambda>365 \mathrm{~nm}$. Such wavelengths helped us to conduct the reaction homogenously. ${ }^{44,45}$ The intensity of the UV beam was $800 \mathrm{~mW} \mathrm{~cm}{ }^{-2}$. The irradiation times were: $0,10,20$ and $40 \mathrm{~min}$ in total at $0.1 \mathrm{MPa} ; 0,10,30,60$ and $120 \mathrm{~min}$ in total at $0.55 \mathrm{GPa} ; 0,15,30,60,90,120$ and $180 \mathrm{~min}$ in total at $0.90 \mathrm{GPa} ; 0,30,90,180$ and $300 \mathrm{~min}$ in total at $1.27 \mathrm{GPa}$; , 40,80 and $150 \mathrm{~min}$ in total at $1.50 \mathrm{GPa}$. The structure of the non-irradiated crystal of the studied compound at ambient pressure has been published previously. ${ }^{46}$ We redetermined it to ensure that all of the data were from the same sample. The structures were solved by means of SHELXS97 and refined using SHELXL97. ${ }^{47}$ The crystal data obtained at 0.90(2) GPa, at ambient pressure for $40 \mathrm{~min}$ UV irradiation and at $1.50 \mathrm{GPa}$ for $150 \mathrm{~min}$ UV irradiation were not of satisfactory quality and were omitted in the paper. The final refined values of the site occupation factor revealed the following content of the product: $0,5.9(5)$, and $10.6(6) \%$ for the crystal at $0.1 \mathrm{MPa}$; $0,7.3(6), 15.4(9), 44.0(13)$, and $100 \%$ for the crystal at $0.55 \mathrm{GPa} ; 0,7.8(6), 20.5(10), 51.9(16)$, and $100 \%$ for the crystal at $1.27 \mathrm{GPa}$ and $0,11.2(9)$ and $23.8(12) \%$ for the crystal at $1.50 \mathrm{GPa}$. Owing to a reactant-product disorder, the following weak restraints from SHELXL9 $7^{47}$ were applied: DFIX, DANG and SIMU. The target values of the bond lengths and valence angles were taken from the structures of the pure reactant and pure product crystals.

Some non-hydrogen atoms of the major component were refined anisotropically, but all of the atoms of the minor component were treated isotropically. Hydrogen atoms were positioned geometrically with $U_{\text {iso }}=1.2 U_{\text {eq }}$ for benzene rings and $U_{\text {iso }}=1.5 U_{\mathrm{eq}}$ for methyl groups. The hydrogen atom from the hydroxyl group in the product molecule was omitted in the case of all partly reacted crystals. For the pure product crystals, it was located in difference Fourier maps.

Selected experimental data are presented in Table 1 for the structures at $0.55 \mathrm{GPa}$. Data for all structures are given in the cif files. 
(a)

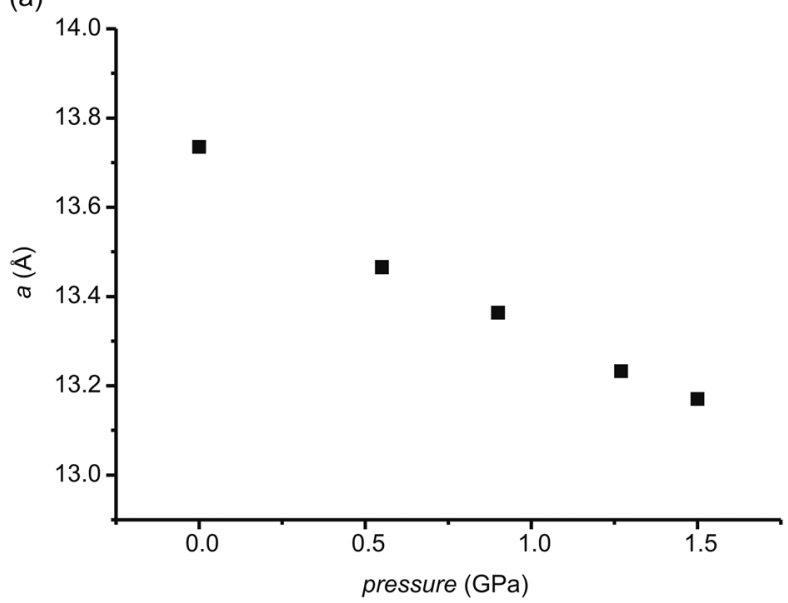

(c)

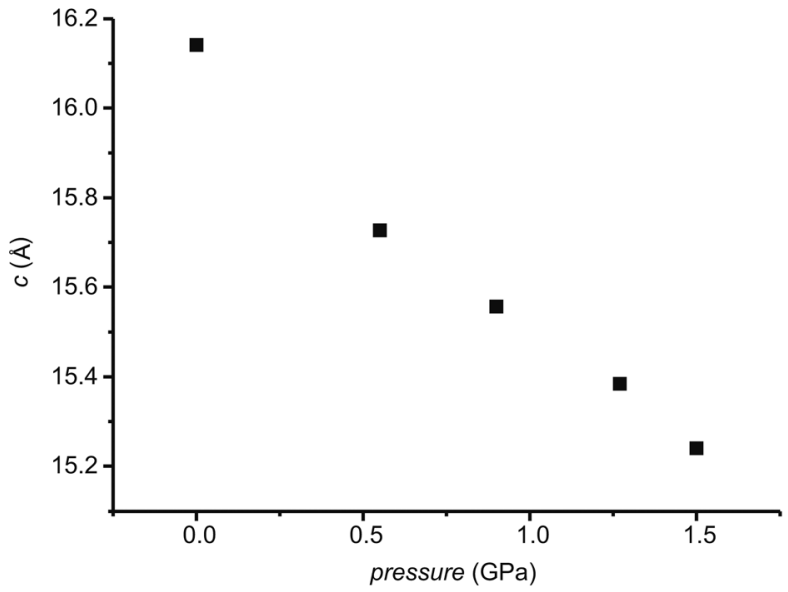

(b)

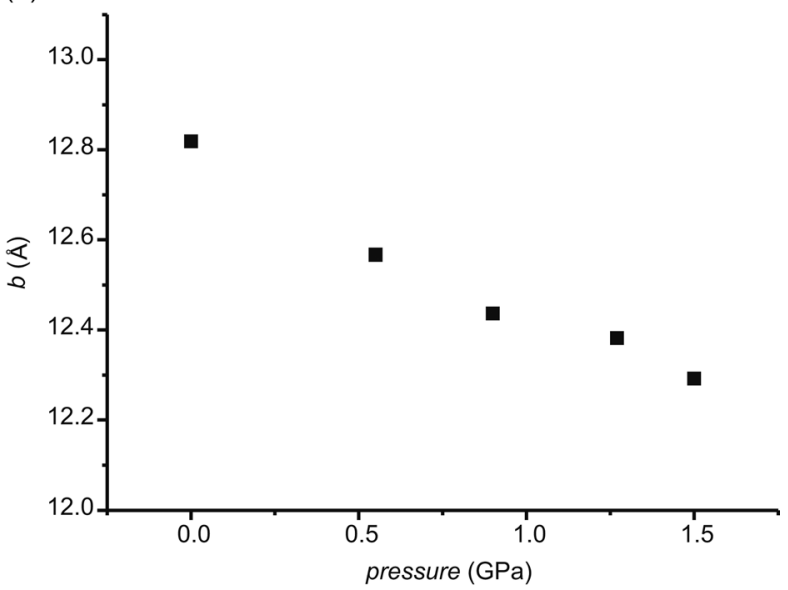

(d)

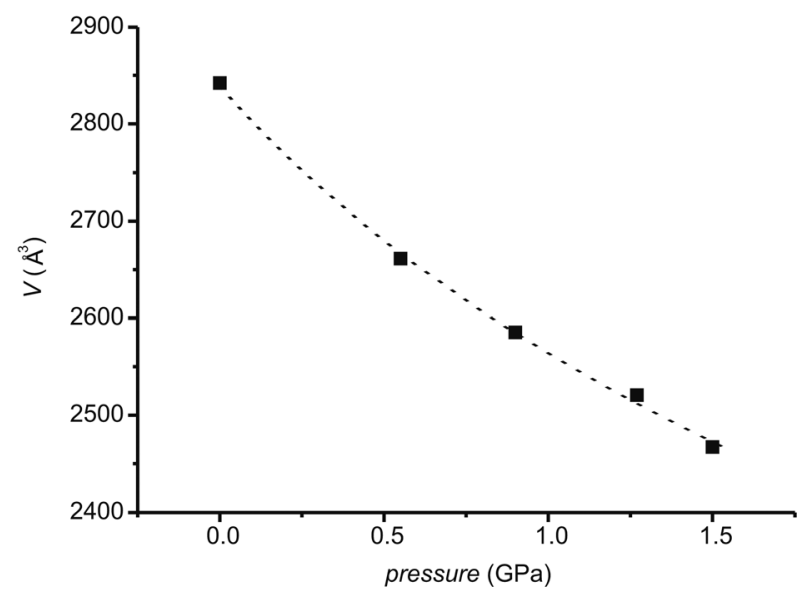

Fig. 2 Variations in the unit cell parameters and cell volume with pressure. For better comparison the range of the axes for plots (a-c) was set to be the same. The dotted line denotes the least-squares Birch-Murnaghan fit to the data. Standard uncertainties for $a, b, c$ and $V$ are in the ranges $0.0009-0.002,0.0006-0.003,0.0010-0.0014 \AA$ and $0.3-0.7 \AA^{3}$, respectively.

In order to check whether the photochemical reaction stops after the removal of the source of UV radiation, an additional data collection was carried out $24 \mathrm{~h}$ after the data collection for one of the partly reacted crystals. The content of the product, determined during the structure refinement, was statistically the same for both data sets. This also showed that the photochemical reaction was not influenced by X-rays.

\section{Results and discussion}

Under satisfactory conditions 2-tert-butylphenylphenylmethanone, the studied compound, can undergo a photocyclization reaction in crystals (Scheme $1 \mathrm{~b}$ and $\mathrm{c}$ ). In this reaction, a $\delta$-H atom is transferred to a carbonyl group and as a result a 1,5-diradical is formed which afterwards can lead to the formation of a fivemembered ring.

Fig. 1a shows the DAC used in the high pressure studies and a typical collection of crystals placed in a metal gasket in the DAC, namely a crystal of the studied compound and additionally ruby and quartz crystals used as pressure sensors.
Fig. 1b presents the structures of the molecules present in a pure reactant crystal, in one of the partly reacted crystals and in a pure product crystal at high pressure. It is noticeable that the shapes of the reactant and product molecules are very similar and also that the phenyl ring moved more in the reaction than the 2-tert-butylphenyl moiety did.

\section{Structural changes brought about by pressure, without photo-induction}

Fig. 2 shows the variations in the unit cell parameters and the unit cell volume with the pressure imposed on the crystals. The changes in the $a, b$ and $c$ parameters en route from the ambient pressure to the pressure of $1.50 \mathrm{GPa}$ are -0.572 , -0.517 and $-0.907 \AA$, which is equivalent to $4.2,4.0$ and $5.6 \%$, respectively. The decrease in the percentage of the unit cell parameters along the $a$ and $b$ axis is very similar. A rather large change in the cell volume, $13.2 \%$, is not unusual for molecular compounds. ${ }^{49,50}$ The changes in the cell parameters are not linear and are bigger at the beginning of the pressure imposition. This is understandable since intermolecular 

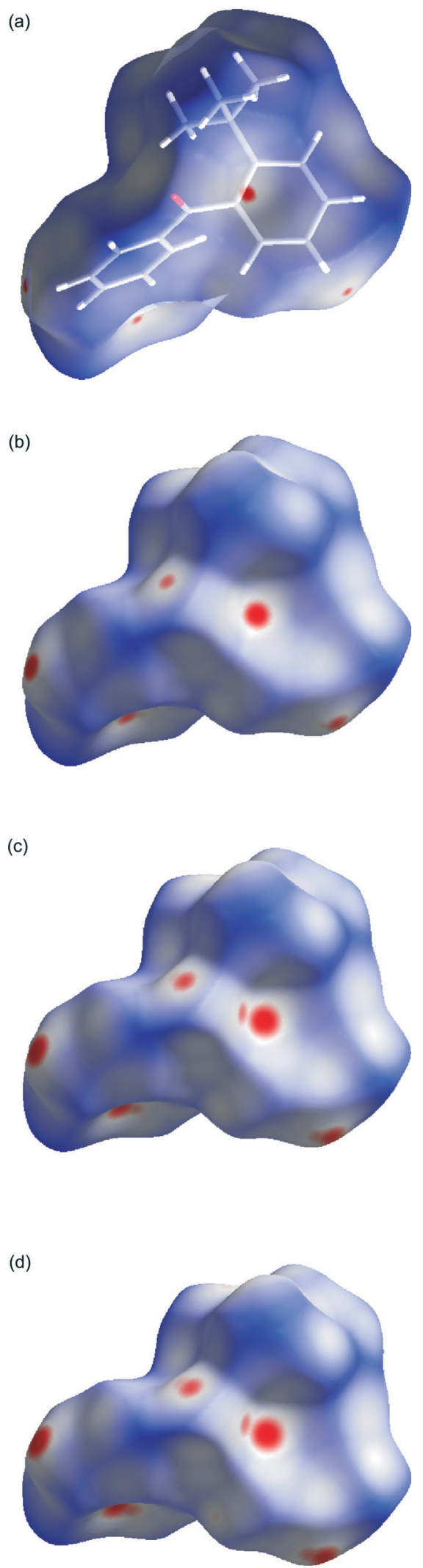

Fig. 3 The Hirshfeld surfaces for the crystals studied at (a) $0.1 \mathrm{MPa}$, (b) $0.55 \mathrm{GPa}$, (c) $1.27 \mathrm{GPa}$ and (d) $1.50 \mathrm{GPa}$, calculated as $d_{\text {norm }}$ by the CrystalExplorer program. ${ }^{54}$ The red colour denotes the intermolecular contacts that are shorter than the sum of the van der Waals radii of interacting atoms, white is for the van der Waals contacts and blue is for the longer contacts. distances are longer at lower pressures and it is easier to shorten them. The pressure-volume data are in agreement with the Birch-Murnaghan equation of state: ${ }^{51}$

$$
P=3 / 2 K_{0}\left[\left(V_{0} / V\right)^{7 / 3}-\left(V_{0} / V\right)^{5 / 3}\right]\left\{1-3 / 4\left(4-K_{0}^{\prime}\right)\left[\left(V_{0} / V\right)^{2 / 3}-1\right]\right\},
$$

where:

$V_{0}$ - the cell volume at ambient pressure,

$K_{0}$ - the ambient-pressure bulk modulus (incompressibility) and

$K_{0}^{\prime}$ - the pressure derivative of incompressibility.

The least-squares fit of the pressure-volume (compression) data for the studied compound to the Birch-Murnaghan equation of state gave $K_{0}=7.3 \mathrm{GPa}$ and $K_{0}^{\prime}=5.4 \mathrm{GPa}$.

The intermolecular distances were also visualized by the Hirshfeld surfaces ${ }^{52,53}$ in Fig. 3. As can be seen, big changes take place near the reaction centre.

The variations in the unit cell parameters and the cell volume are smooth, which indicates that no phase transition takes place in the pressure range from ambient to $1.50 \mathrm{GPa}$. A smooth relationship is also observed between the values of the free space in the crystals and the values of the pressure, which is shown in Fig. 4a. This also indicates that there is no phase transition brought about by a change in pressure. From Fig. $4 \mathrm{~b}$, showing the free space in the unit cell, it can be seen how much free space decreases in the proximity of the molecules, especially near the phenyl and 2-tert-butylphenyl fragments, with an increase in pressure.

The orientation of the molecules in the crystals does not change significantly en route from $0.1 \mathrm{MPa}$ to $1.50 \mathrm{GPa}$. The biggest change observed is for the benzene ring, $1.4^{\circ}$, but the change in orientation proceeds in a smooth manner (shown in Fig. 5a).

High pressure influenced not only the intermolecular distances but also the intramolecular non-bonding contacts: for instance, the distance between the carbon atoms which take part in the formation of a five-membered ring in the photochemical reaction, $D$ in Fig. $5 \mathrm{~b}$. As can be seen, $D$ is almost constant for lower values of pressure and changes only at high values. High pressure is not able to significantly change the dihedral angle between the planes of both of the benzene rings in the molecules. This angle decreases only by $1.1^{\circ}$ en route from $0.1 \mathrm{MPa}$ to $1.50 \mathrm{GPa}$, but nevertheless even this decrease proceeds in a smooth manner.

\section{Photo-induced structural changes at different pressures}

Changes in the unit cell parameters. For many steps of the photochemical reaction and crystal transformation at various pressures, we determined the cell parameters and crystal structures. Due to the photochemical reaction, the positions of the atoms and molecules change and these shifts are manifested in the cell parameters. Fig. 6 presents the changes in unit cell parameters resulting from the photochemical reaction carried out at $0.55 \mathrm{GPa}$ and $1.27 \mathrm{GPa}$. As can be seen, the variations in the cell parameters are 
(a)

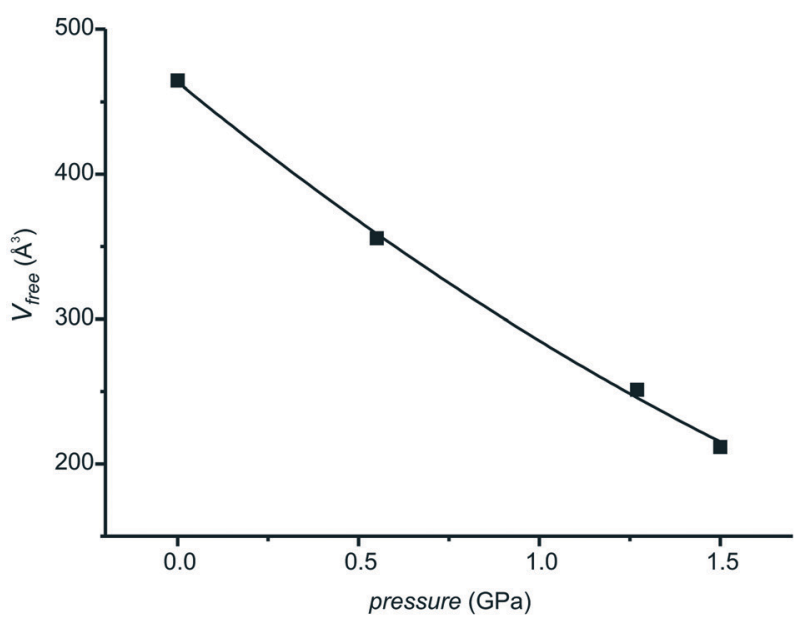

(b)

$0.1 \mathrm{MPa}$

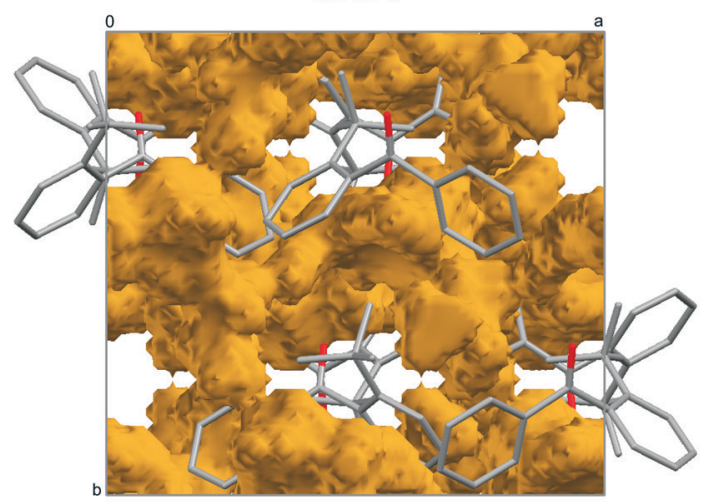

$1.27 \mathrm{GPa}$

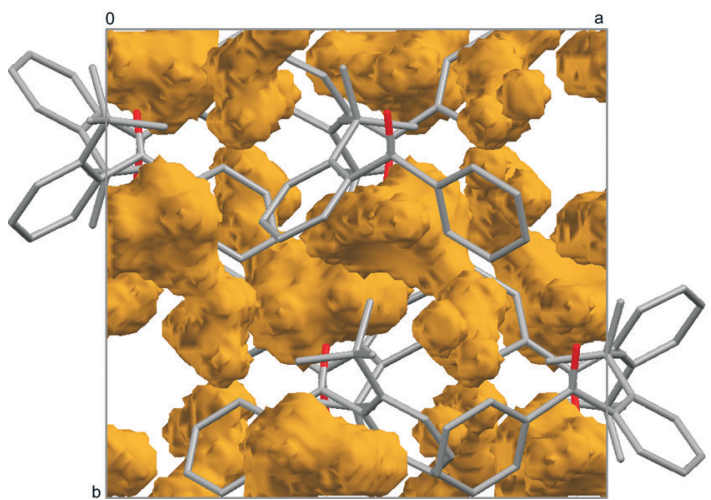

$0.55 \mathrm{GPa}$

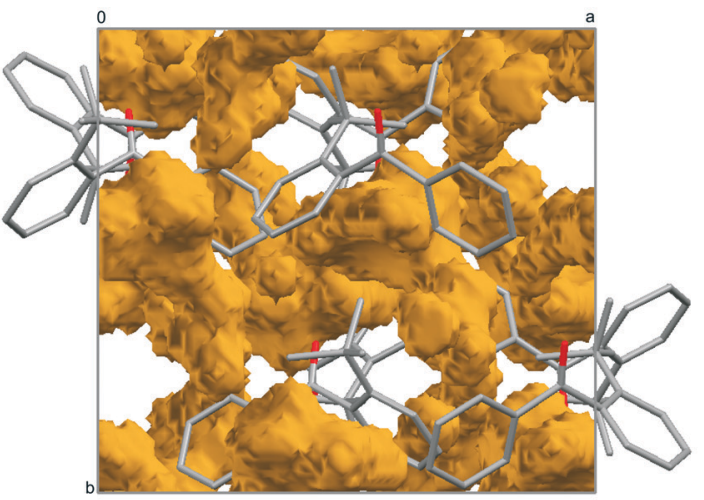

$1.50 \mathrm{GPa}$

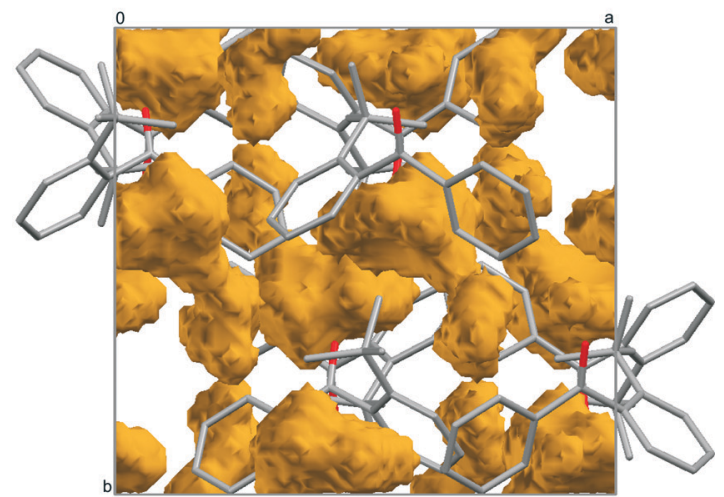

Fig. 4 (a) Relationship between the free space in the unit cell and the pressure. (b) The free space for the crystals studied at $0.1 \mathrm{MPa}$, $0.55 \mathrm{GPa}$, $1.27 \mathrm{GPa}$ and $1.50 \mathrm{GPa}$. The rolling ball method from the Mercury program ${ }^{55}$ was applied; the ball radius and grid were 0.6 and $0.2 \AA$, respectively.

smooth as the photochemical reaction progresses, however, the same parameters do not change in the same way for both pressures. Interestingly, parameter $b$ changes more at the higher pressure but the character of the changes in $c$ is not the same: $c$ decreases at the lower pressure and slightly increases at the higher pressure. The percentage change in $a$ is similar for both pressures. At $0.55 \mathrm{GPa}$ the photochemical reaction brings about the following changes in $a, b$ and $c$ : $3.0,-1.8,-0.5 \%$, respectively. For $1.27 \mathrm{GPa}$, the changes for the same unit cell parameters are: $3.2,-3.0$ and $0.2 \%$. They lead to the following changes in the cell volume: $0.6\left(16.3 \AA^{3}\right)$ and $0.4 \%\left(10.7 \AA^{3}\right)$ for $0.55 \mathrm{GPa}$ and $1.27 \mathrm{GPa}$, respectively. 
(a)

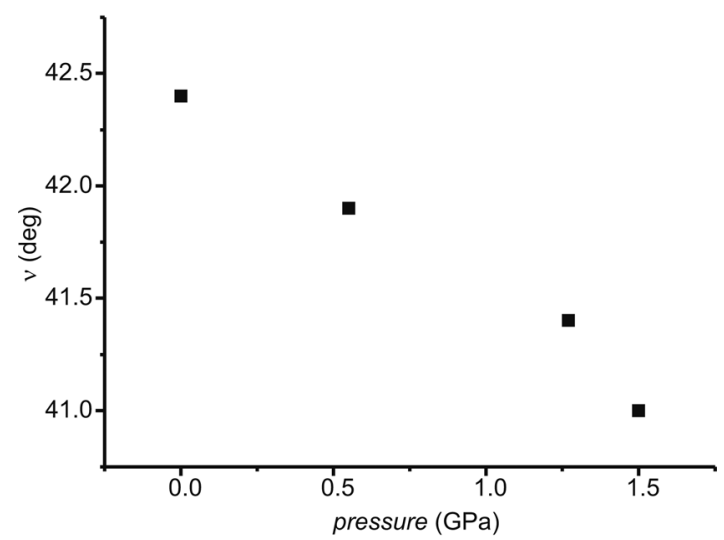

(b)

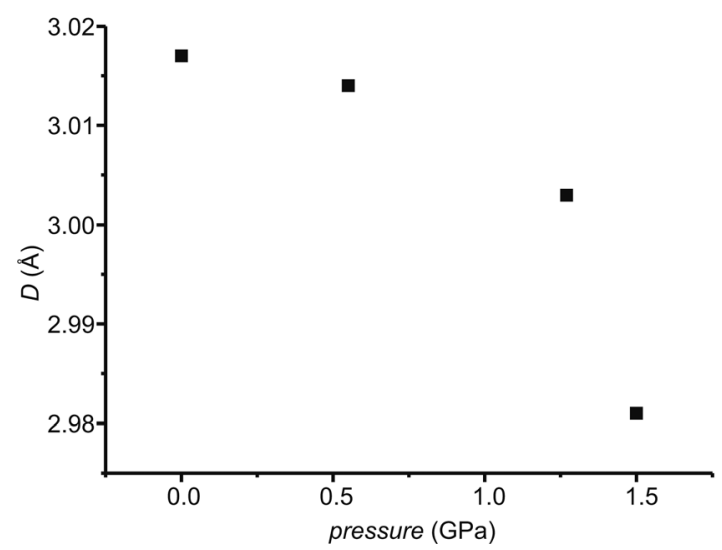

Fig. 5 Variations in (a) the angle between the benzene ring and the $a b$ plane, and (b) the distance between the reactive atoms with pressure. Standard uncertainties for the distance are in the range of $0.005-0.008 \AA$.

The changes in the cell volume are smaller at the high pressure than at ambient pressure, however, the percentage change is similar for both cases.

Changes in molecular orientation. The photochemical reaction conducted in crystals only brings about small changes in the orientation of the reactant molecules as it was in the case of the pressure-induced structural changes (see above Fig. 5a). The biggest changes in the orientation of the benzene ring in the reactant molecules were $1.7^{\circ}$ and $2.6^{\circ}$ as the reaction progressed for $0.55 \mathrm{GPa}$ and $1.27 \mathrm{GPa}$, respectively. These changes were monitored en route from the beginning of the photoreaction until ca. $50 \%$ of the reaction had occurred. The behaviour of the product molecules was monitored from $\mathrm{ca} .10 \%$ of the reaction progress until the end of the reaction. The biggest changes in the orientation of the benzene ring of the product molecules were $11.4^{\circ}$ and $9.2^{\circ}$ in the monitored region for $0.55 \mathrm{GPa}$ and $1.27 \mathrm{GPa}$, respectively. An example of such relationships is shown in Fig. 7. As we can see, the changes observed are smooth.

Kinetics of the photochemical reaction. Knowledge on the content of the product in partly reacted crystals, gained during the structure determination, allowed us to calculate the values of the reaction order, $n$, at different pressures using the Johnson-Mehl-Avrami-Kolmogorov (JMAK) model. ${ }^{56-58}$ This method has been applied to several photochemical reactions in crystals. ${ }^{59-62}$ In a previous paper ${ }^{62}$ we pointed out that product formation should be described by the following equation:

$$
P=1-\exp \left[-(k t)^{n}\right]
$$

where:

$P$ - the fraction of a product in a crystal,

$k$ - the rate constant of a photochemical reaction,

$t$ - the time of irradiation of a crystal and

$n$ - the Avrami exponent describing the dimensionality of growth of nuclei.

The values of $n$ equal to 1, 2, 3 or 4 prove that the formation of a product in crystals is homogenous, linear, twodimensional or three-dimensional, respectively. Intermediate values indicate a hybrid mechanism.

In the case of the crystals studied in this work, the values of $n$ are: $0.9,1.1(3), 1.2(2)$ and 1.2 for $0.1 \mathrm{MPa}, 0.55 \mathrm{GPa}$, 1.27 GPa and 1.50 GPa, respectively. They indicate that the photochemical reaction in the examined crystals was mainly conducted in a homogenous manner.

Fig. 8 reveals the changes in the content of the product molecules in the crystal along with the time of irradiation of the crystal at pressures of $0.55 \mathrm{GPa}$ and $1.27 \mathrm{GPa}$. As can be seen, the relationships are neither exponential nor linear, which indicates that the photochemical reaction is neither first nor zero order. For both pressures the photochemical reaction proceeds faster at the end rather than at the beginning. In the case of the Norrish-Yang reaction conducted at ambient pressure in $\alpha$-methylbenzylamine salt with 1-(4-carboxybenzoyl)-1-methyladamantane, ${ }^{7}$ the salt of 6,6-diethyl-5-oxo-5,6,7,8-tetrahydronaphthalene-2-carboxylic acid with (1S)-1-(4-methylphenyl)-ethylamine ${ }^{9}$ and methyl $2-\{[4-(2,4,6$-triisopropylbenzoyl)benzoyl $]$ amino\}-3-phenylpropanoate (enantiomeric form) ${ }^{10}$ we observed exponential relationships. However, for methyl 2-\{[4-(2,4,6-triisopropylbenzoyl)benzoyl $]$ amino\}-3-phenylpropanoate (racemic form) ${ }^{10}$ the relationship between the content of the product and the time of irradiation has a character similar to that observed for the compound studied in this work, i.e. the reaction speeds up at the end. Now, we can generalize these observations in the following way. For all reactions characterized by exponential relationships, the distance between the reactive atoms in reactant molecules, $D$, is constant during the whole or almost the whole crystal phototransformation., ${ }^{7,9,10}$ This is not the case for the compounds where an increase in the speed of the reaction rate is observed. For them, $D$ is not constant but decreases. ${ }^{10}$ (In general, smaller distances between reactive atoms are expected to increase the rates of photochemical reactions.) The decrease in $D$ is also observed for the compound studied in this paper, namely from 3.014(5) $\AA$ (0\% reaction progress) to $2.942(18) \AA$ ( $44.0 \%$ reaction progress) at a pressure of $0.55 \mathrm{GPa}$ and from $3.004(5) \AA$ (0\% reaction progress) to $2.88(3) \AA$ (51.9\% reaction progress) at $1.27 \mathrm{GPa}$. 
(a)
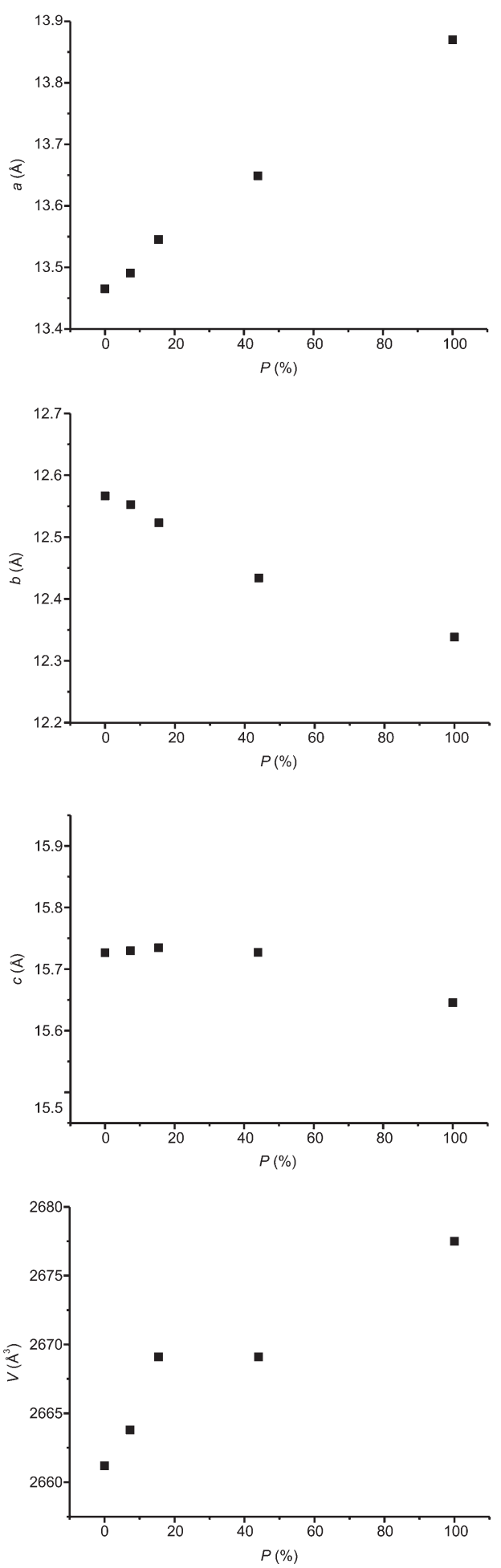
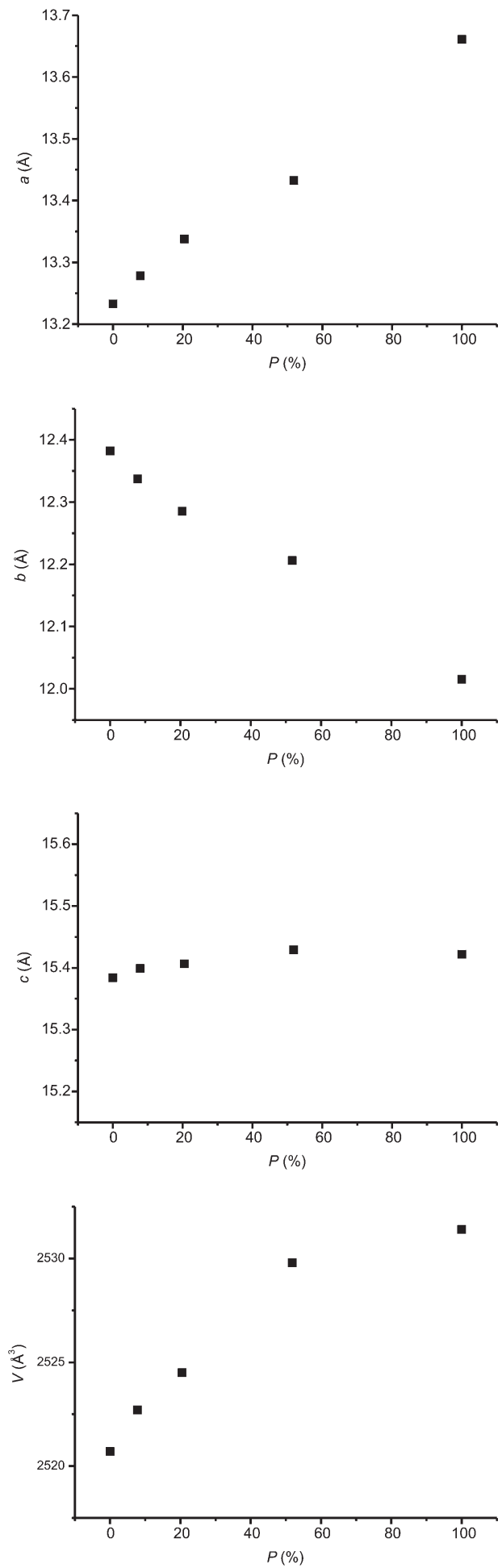

Fig. 6 Variations in the unit cell parameters and cell volume with the photoproduct content in the crystals (a) at $0.55 \mathrm{GPa}$ and (b) $1.27 \mathrm{GPa}$.

\section{Conclusions}

The analysis of intra- and intermolecular geometrical parameters for many stages of the photocyclization of 2-tertbutylphenylphenylmethanone provided information on the changes in a reaction centre, molecules and crystals and information on the influence of external factors, namely pressure. The studies showed that (a) the photochemical reaction carried out for the compound investigated brings about different modes of changes in the unit cell parameters 
(a)

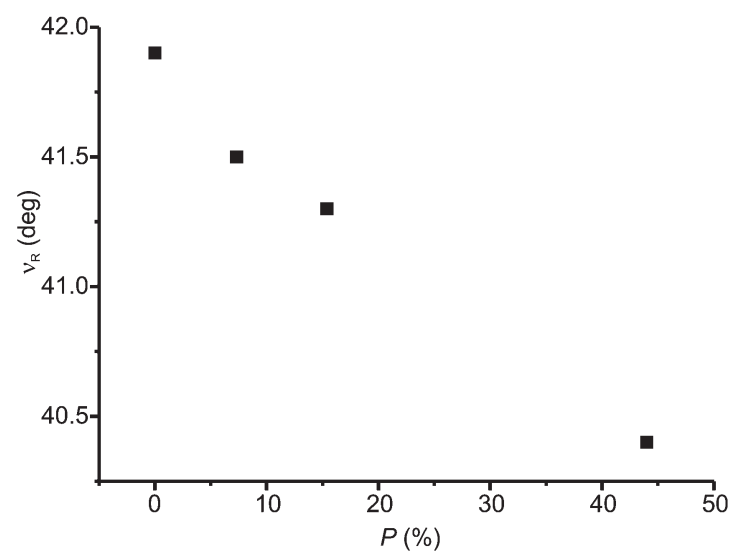

(b)

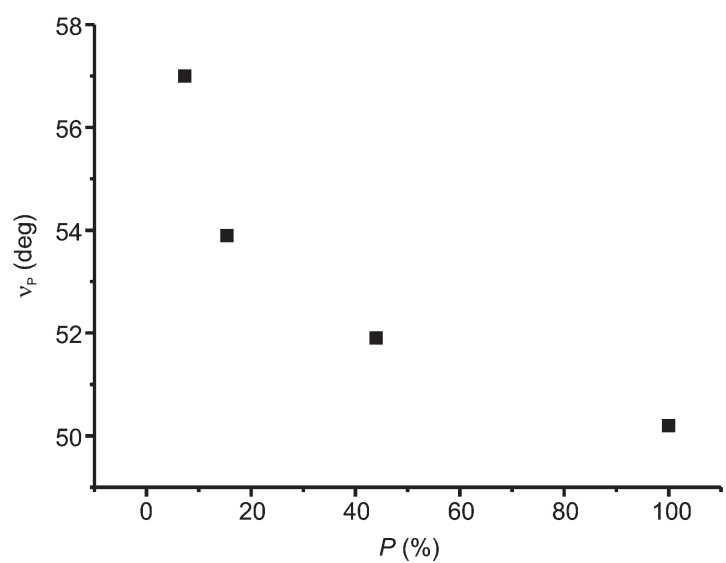

Fig. 7 Variations in the angle between the benzene ring of (a) the reactant and (b) product molecule and the $a b$ plane.

at different pressures, (b) the reaction proceeds faster at the end than at the beginning, regardless of the pressure imposed onto the crystals, (c) the reaction was conducted in a homogeneous manner (d) there is no phase transition when an increase in pressure is imposed onto the crystals.

Further research on other compounds and other types of photochemical reactions (intra- and intermolecular) will enable a better understanding of the influence of external factors, namely pressure, on the reactions in crystals and the paths of transformations of crystals.

\section{Acknowledgements}

The work was carried out with the grant 2011/01/D/ST5/02834 financed by the National Science Centre (Poland) and the fellowship was co-financed by the European Union with the European Social Fund (Wrocław University of Technology, Poland). The authors thank Prof. A. Katrusiak for a discussion concerning data collection strategy at high-pressure and Dr E. Zienkiewicz for help with the Birch-Murnaghan fit. (a)

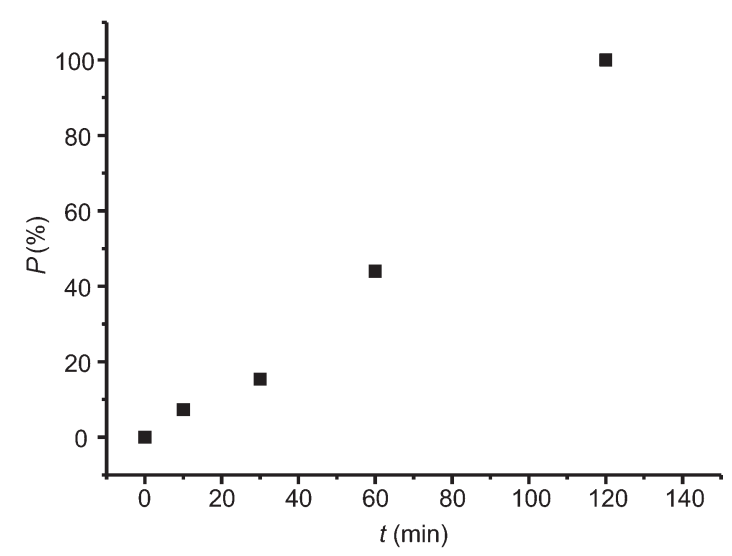

(b)

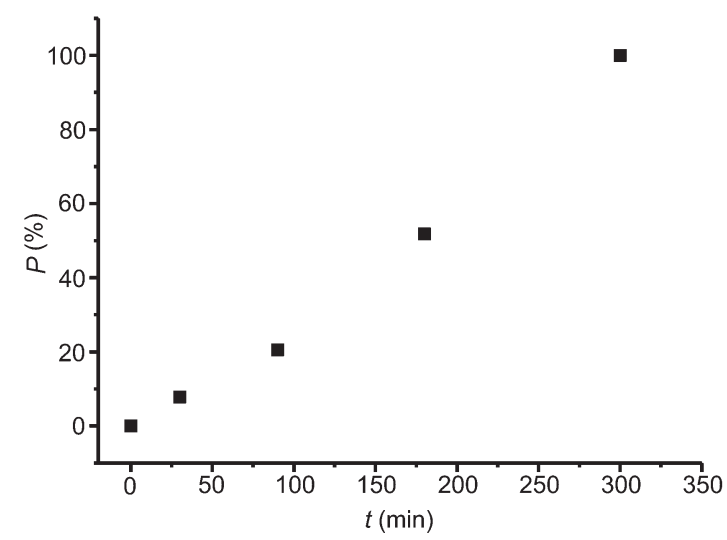

Fig. 8 Relationship between the product content in the crystal at (a) $0.55 \mathrm{GPa}$ and (b) $1.27 \mathrm{GPa}$ and the time of UV irradiation.

\section{References}

1 I. Turowska-Tyrk, Chem. - Eur. J., 2001, 7, 3401-3405.

2 I. Turowska-Tyrk, Acta Crystallogr., Sect. B: Struct. Sci., 2003, 59, 670-675.

3 I. Turowska-Tyrk and E. Trzop, Acta Crystallogr., Sect. B: Struct. Sci., 2003, 59, 779-786.

4 S. Ohba and Y. Ito, Acta Crystallogr., Sect. B: Struct. Sci., 2003, 59, 149-155.

5 M. A. Fernandes and D. C. Levendis, Acta Crystallogr., Sect. B: Struct. Sci., 2004, 60, 315-324.

6 J. B. Benedict and P. Coppens, J. Phys. Chem. A, 2009, 113, 3116-3120.

7 I. Turowska-Tyrk, E. Trzop, J. R. Scheffer and S. Chen, Acta Crystallogr., Sect. B: Struct. Sci., 2006, 62, 128-134.

8 I. Turowska-Tyrk, I. Łabęcka, J. R. Scheffer and W. Xia, Pol. J. Chem., 2007, 81, 813-824.

9 I. Turowska-Tyrk, J. Backowicz and J. R. Scheffer, Acta Crystallogr., Sect. B: Struct. Sci., 2007, 63, 933-940.

10 J. Bąkowicz, J. Skarżewski and I. Turowska-Tyrk, CrystEngComm, 2011, 13, 4332-4338.

11 S. Zheng, M. Messerschmidt and P. Coppens, Acta Crystallogr., Sect. B: Struct. Sci., 2007, 63, 644-649. 
12 S. Zheng, M. Messerschmidt and P. Coppens, Chem. Commun., 2007, 2735-2737.

13 S. Zheng, C. M. L. Vande Velde, M. Messerschmidt, A. Volkov, M. Gembicky and P. Coppens, Chem. - Eur. J., 2008, 14, 706-713.

14 P. Coppens, S. Zheng and M. Gembicky, Z. Kristallogr., 2008, 223, 265-271.

15 E. V. Boldyreva, in Reactivity of Solids. Past, Present, Future, ed. V. Boldyrev, IUPAC Series, 1996, pp. 141-184.

16 E. V. Boldyreva, Solid State Ionics, 1997, 101-103, 843-849.

17 V. Schettino and R. Bini, Phys. Chem. Chem. Phys., 2003, 5, 1951-1965.

18 R. Bini, Acc. Chem. Res., 2004, 37, 95-101.

19 K. Aoki, S. Usuba, M. Yoshida, Y. Kakudate, K. Tanaka and S. Fujiwara, J. Chem. Phys., 1988, 89, 529-534.

20 D. Chelazzi, M. Ceppatelli, M. Santoro, R. Bini and V. Schettino, Nat. Mater., 2004, 3, 470-475.

21 D. Chelazzi, M. Ceppatelli, M. Santoro, R. Bini and V. Schettino, J. Phys. Chem. B, 2005, 109, 21658-21663.

22 M. Santoro, L. Ciabini, R. Bini and V. Schettino, J. Raman Spectrosc., 2003, 34, 557-566.

23 M. Ceppatelli, M. Santoro, R. Bini and V. Schettino, J. Chem. Phys., 2000, 113, 5991-6000.

24 M. Sakashita, H. Yamawaki and K. Aoki, J. Phys. Chem., 1996, 100, 9943-9947.

25 C. C. Trout and J. V. Badding, J. Phys. Chem. A, 2000, 104, 8142-8145.

26 M. Mugnai, M. Pagliai, G. Cardini and V. Schettino, J. Chem. Theory Comput., 2008, 4, 646-651.

27 J. M. Besson, M. M. Thiery and P. Pruzan in Molecular Systems Under High Pressure, ed. R. Pucci and G. Piccitto, Elsevier, Amsterdam, 1991, p. 341.

28 L. Ciabini, M. Santoro, R. Bini and V. Schettino, J. Chem. Phys., 2002, 116, 2928-2935.

29 P. Pruzan, J. C. Chervin, M. M. Thiery, J. P. Itie and J. M. Besson, J. Chem. Phys., 1990, 92, 6910-6915.

30 L. Ciabini, M. Santoro, F. A. Gorelli, R. Bini, V. Schettino and S. Raugei, Nat. Mater., 2007, 6, 39-43.

31 L. Ciabini, M. Santoro, R. Bini and V. Schettino, Phys. Rev. Lett., 2002, 88, 085505.

32 M. Ceppatelli, M. Santoro, R. Bini and V. Schettino, J. Chem. Phys., 2003, 118, 1499-1506.

33 M. Santoro, M. Ceppatelli, R. Bini and V. Schettino, J. Chem. Phys., 2003, 118, 8321-8325.

34 Ph. Pruzan, J. C. Chervin and J. P. Forgerit, J. Chem. Phys., 1992, 96, 761-767.

35 V. Schettino, R. Bini, G. Cardini, M. Ceppatelli, M. Citroni and M. Pagliai, Il Nuovo Cimento B, 2008, 123, 1399-1414.

36 M. Citroni, M. Ceppatelli, R. Bini and V. Schettino, Science, 2002, 295(5562), 2058-2060.

37 M. Citroni, M. Ceppatelli, R. Bini and V. Schettino, J. Chem. Phys., 2003, 118, 1815-1820.
38 R. Boehler, Rev. Sci. Instrum., 2006, 77, 115103.

39 G. J. Piermarini, S. Block, J. D. Barnett and R. A. Forman, J. Appl. Phys., 1975, 46, 2774-2780.

40 H. K. Mao, J. Xu and P. M. Bell, J. Geophys. Res., 1986, 91, 4673-4676.

41 R. J. Angel, D. R. Allan, R. Miletich and W. Finger, J. Appl. Crystallogr., 1997, 30, 461-466.

42 A. Budzianowski and A. Katrusiak in High-Pressure Crystallography, ed. A. Katrusiak and P. F. McMillan, Kluwer Academic Publishers, Dordrecht Boston London, 2004, pp. 101-112.

43 Oxford Diffraction, CrysAlis CCD and CrysAlis RED, Oxford Diffraction Ltd., Abingdon, England, 2006.

44 V. Enkelman, G. Wegner, K. Novak and K. B. Wagener, J. Am. Chem. Soc., 1993, 115, 10390-10391.

45 K. Novak, V. Enkelmann, G. Wegner and K. B. Wagener, Angew. Chem., Int. Ed. Engl., 1993, 32, 1614-1616.

46 P. J. Wagner, B. P. Giri, J. C. Scaiano, D. L. Ward, E. Gabe and F. L. Lee, J. Am. Chem. Soc., 1985, 107, 5483-5490.

47 G. M. Sheldrick, Acta Crystallogr., Sect. A: Found. Crystallogr., 2008, 64, 112-122.

48 L. J. Farrugia, J. Appl. Crystallogr., 1997, 30, 565.

49 A. Budzianowski, A. Olejniczak and A. Katrusiak, Acta Crystallogr., Sect. B: Struct. Sci., 2006, 62, 1078-1089.

50 E. V. Boldyreva, T. N. Drebushchak, T. P. Shakhtshneider, H. Sowa, H. Ahsbahs, S. V. Goryainow, S. N. Ivashevskaya, E. N. Kolesnik, V. A. Drebushchak and E. B. Burgina, ARKIVOC XII, 2004, pp. 128-155.

51 F. Birch, Phys. Rev., 1947, 71, 809-824.

52 J. Bernstein, Cryst. Growth Des., 2011, 11, 632-650.

53 M. A. Spackman and D. Jayatilaka, CrystEngComm, 2009, 11, 19-32.

54 S. K. Wolff, D. J. Grimwood, J. J. McKinnon, M. J. Turner, D. Jayatilaka and M. A. Spackman, CrystalExplorer (Version 3.0), University of Western Australia, 2012.

55 C. F. Macrae, P. R. Edgington, P. McCabe, E. Pidcock, G. P. Shields, R. Taylor, M. Towler and J. van de Streek, J. Appl. Crystallogr., 2006, 39, 453-457.

56 M. Avrami, J. Chem. Phys., 1939, 7, 1103-1112.

57 W. A. Johnson and R. F. Mehl, Trans. AIME, 1939, 135, 416-458.

58 A. N. Kolmogorov, Izv. Akad. Nauk SSSR Ser. Mat., 1937, 1, 355-359.

59 M. Bertmer, R. C. Nieuwendaal, A. B. Barnes and S. E. Hayes, J. Phys. Chem. B, 2006, 110, 6270-6273.

60 A. G. Jarvis, H. A. Sparkes, S. E. Tallentire, L. E. Hatcher, M. R. Warren, P. R. Raithby, D. R. Allan, A. C. Whitwood, M. C. R. Cockett, S. B. Duckett, J. L. Clark and I. J. S. Fairlamb, CrystEngComm, 2012, 14, 5564-5571.

61 J. Kohout, J. Mater. Sci., 2008, 43, 1334-1339.

62 J. Bąkowicz, J. Olejarz and I. Turowska-Tyrk, J. Photochem. Photobiol., A, 2014, 273, 34-42. 